\title{
An Adaptive Reusable Learning ObJect For E-LEARNINg USING COGNITIVE ARCHITECTURE
}

\author{
A.Kanimozhi ${ }^{1}$ and Dr.V.Cyrilraj ${ }^{2}$ \\ ${ }^{1}$ Department of Computer and Engineering, Sathyabama University, Chennai, India \\ ${ }^{2}$ HOD/CSE, Dr.M.G.R Educational and Research Institute, Chennai, India
}

\begin{abstract}
Nowadays, a huge amount of ambiguous e-learning materials are available in World Wide Web irrespective of various objectives. These digital educational resources can be reused and shared from centralized online repository and it will avoid the redundant learning material. The main goal is to design consistent adaptable e-learning course material for web-based education system with emphasis on the quality of learning. This can be done by organizing learning object in a prescribed manner and it can be reused in feature. Such reusable learning objects are enhanced further to become adaptive reusable learning objects that are virtually cognitive and responsive towards the specific needs of the user/customer. This paper proposes the cognitive architecture to offer an adaptive reusable objects (RLO) based on individual profile of e-learner besides their cognitive behaviour while learning.
\end{abstract}

\section{KEYWORDS}

Reusable Learning Object, Cognitive model, learner behaviour, e-learning

\section{INTRODUCTION}

The rapid development of e-Learning or Web-based learning is always becoming a research area which aims to provide a learning environment as a pedagogical learning. In addition, e-learning allows the learner to learn at any location around the world for 24 hours a day and seven weeks a day.

E-Learning framework includes many components to offer web based learning service such as content delivery in multiple formats, managing learner and their learning experience, content developers and experts. Course development in internet is always a special one. Once the learning content is created and uploaded in one end of the world, the same topic could be accessed by anybody. Therefore, online learning materials may be easily reused but the difficulty to find the appropriate learning materials on the Internet. We should handle the learning material as learning object and organize, disseminate the learning content into a uniform format as small pieces of learning materials. We go for this E-learning repository system based on the current demand and future adoption among students. The eXtensible Markup Language (XML) language adopted by most learning organizations to facilitate significant features of e-Learning framework such as personalization, interoperability, reusability and flexibility [XML 2000][1]. This can be done redefining learning object by generating schema for learning object such as Metadata specification, content specification and learner profile specification are included to make suitable for e-learning systems [2][3]. 
It is common that the reuse of the learning content developed by one vendor or educational institution is difficult to reuse by another vendor or institution, even though the content shares the same meaning and this process of sharing and reusability will reduce the production cost [Downes, 2001]. According to the IEEE Learning Technology Standards Committee, learning objects are defined as an entity which can be used, reused, or referenced in technology-supported learning [LTSC 2002] and the entire learning object must have the description and it should be wrapped with metadata to pick the right object for right job. Metadata is defined as "structured data about data" which can be used to describe resources and that they can be self-defined [Gerber 2001]. Cisco system defined various form of reusable learning object like concept, fact, principle, process, and procedure. This learning object should be objective based object, context free object and interactive object. The word reuse define that, the grouping of learning material from the existing system and the collection of learning content from multiple sources forms a learning object for the new course is called reusable learning object. Many design approaches are available to build a reusable learning object for different courses. However the core idea is how to offer this right object for e-learner based on the learner personalization feature and their cognitive behaviour while learning.

\section{RELATED WORKS}

In E- learning, a database of educational resources is available known as courseware reuse approach (Olimpo, Persico, Sarti, \& Tavella, 1990). This approach was used by ARIADNE (Forte, Forte, \& Duval, 1996) and MTS (Graf \& Schnaider, 1997). The courseware reuse architecture has multiple pools (repositories) of educational material and were indexed with metadata. OOGLOM - Object Oriented Generic Learning Object Model [4][5] is an UML model, which offer sharable learning object content for learner. Learning object Recommendation system [6][7] adaptively monitoring the preference, learner learning style, learner knowledge and other parameter to assign learning material. Many research on Learning Management System (LMS), to offer adaptive reusable learning object based on learner requirements and this environment will also handle learning object in the form of XML documents [8]. Java servlets and Java applet and related interface are used to implement Learning Management System. This system randomly collects the requested learning object from World Wide Web and groups the related object in the name of content packaging file. In addition this system uses many XML schemas to catalogue the learning objects in various aspects such as learning object, metadata, content packaging and learner personalization model. Many no. of learning repositories are available such as MERLOT, CAREO, and Wisconline and the standards for these repositories set by AICC (Aviation Industry Computer-based Training Committee). This object should be SCORM (Sharable Content Object Reference Model), which is developed by Advanced Distributed Learning Initiative (Advanced Distributed Learning, 2004).

\section{Problem Statement}

In e-learning or Web-based learning the learning content retrieval can only be retrieved on demand and the retrieved learning content are packed in the repositories called content packaging file. The users thus were unable to work with highly interactive learning content. The learner not able to continue their learning for certain period of time due to their distraction while learning, so the efficient learning content not able to use by the learner. To overcome this drawback, we need an adaptive cognitive architecture, which can easily track and monitor the learner behaviour as pedagogical tutor and control the learning management system to retain the related learning content as content packaging file and trigger external stimuli to bring back the learner with conscious and focused mood. 


\section{Proposed Architecture}

The continuous enhancements in web based learning, information and communication technologies influence the content developer to create more and more amount of learning material, which leads ambiguity in learning material. We need system to Manage the learning material called as LMS (Learning Management System) or LCMS (Learning Content Management System) [9]. Later for the efficient utilization and sharing of learning object we go for learning object repositories using different technologies. Multi-Adaptive Learning Object Repository (MALOR) is a unified structure for learning object in e-learning [10]

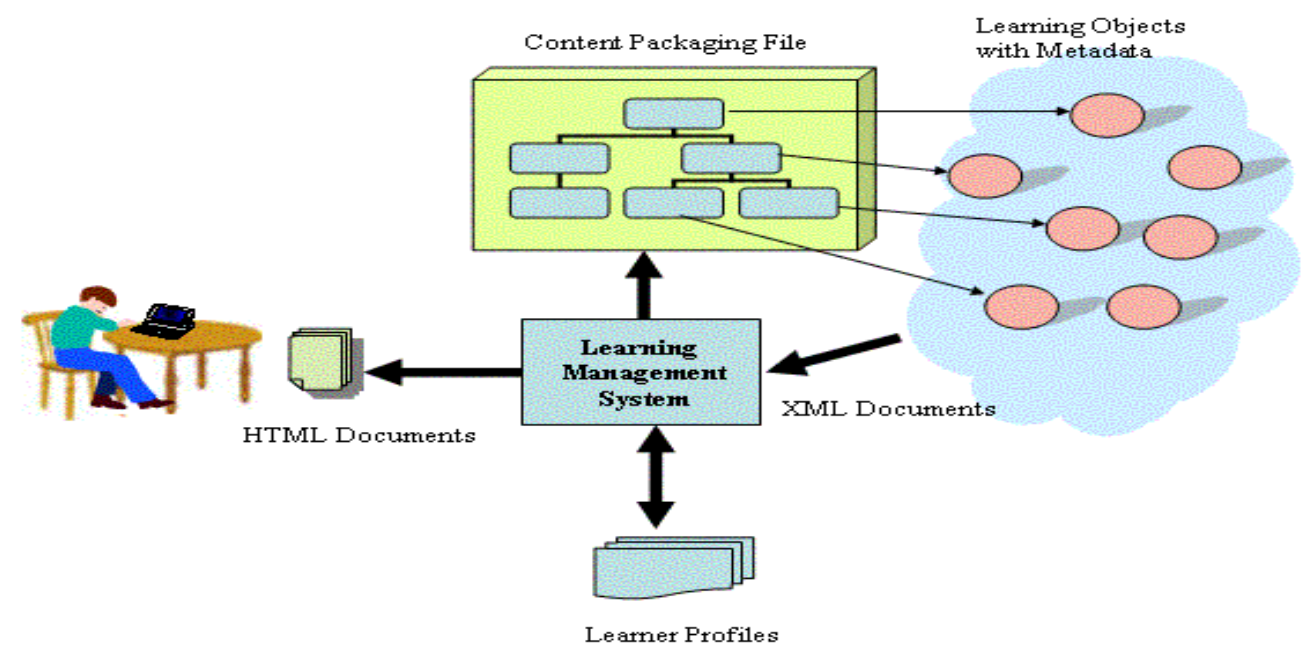

Fig 1. Learning Management System ( Honggang Wu, 2002)

Now the next core idea is how to provide the learning object to e-learner adaptively. For this case, we have to consider many adaptive parameter such as cognitive abilities, learning style, learning behaviour, competence level etc. not only the learner's behaviour also the e-learning system. This system should have four elements like Adaptive content aggregation, Adaptive presentation, Adaptive navigation and Adaptive collaboration support.

A hybrid ACT - R is a theory of cognition developed by John Anderson from Carnegie-Mellon University, which replicates how human beings recollects a lot of information from their memory. ACT-R cognitive architecture efficiently applicable to observe the learner behaviour.

The cognitive architectural components are the modules, important one is the goal module, the goal module described as the declarative memory module and the perceptual-motor modules and each of these modules has corresponding buffer. Information called as chunks. When the cognitive system desires to perform pattern matching, the central production system simple generates production rules and test the rule with appropriate data [11][12]. The Activation of chunk $\mathrm{i}$ is given by

$\mathrm{Ai}=\mathrm{Bi}+\Sigma \mathrm{WjSji}$, where $\quad \mathrm{Bi}=$ Base - level activation of chunk $\mathrm{i}$.

$\mathrm{Wj}=$ Activation spread from linked chunks $\mathrm{j}$. 


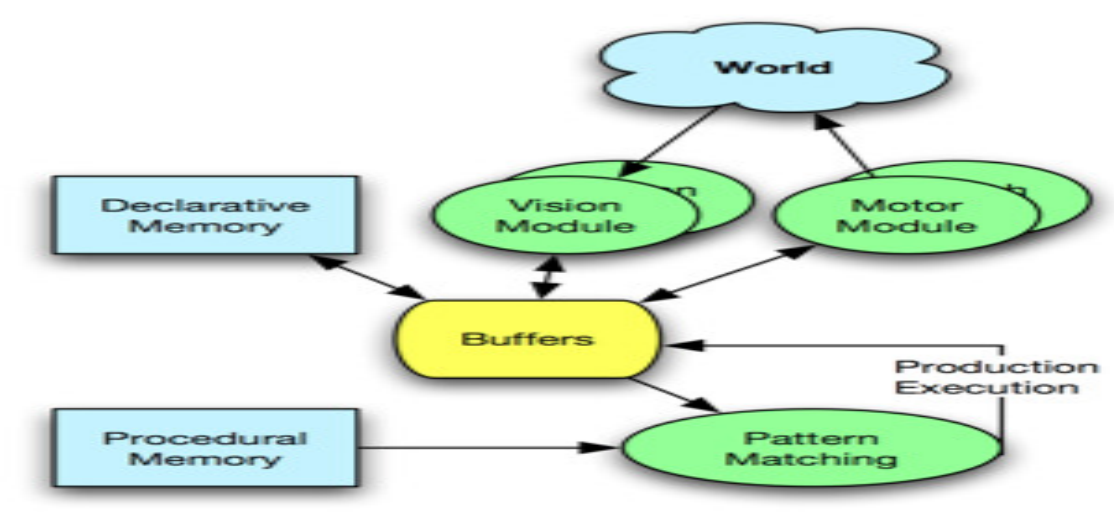

Fig 2. Core components of ACT-R (J.R.Anderson, 2004)

In addition, [13] we add SAM (Self-assessment manikin) as learning repositories for e-learner. This object mainly consist of related videos, audio, presentation, questionaries' etc. When the system feels that the learner not in active listening mood, then the cognitive based e-learning system immediately raise external stimuli. Obviously, when we expose different form of learning material, then immediately the learner come into active listening mood is known as psychological refractory period. (PRP). This period can be easily handled by cognitive architecture ACT-R.

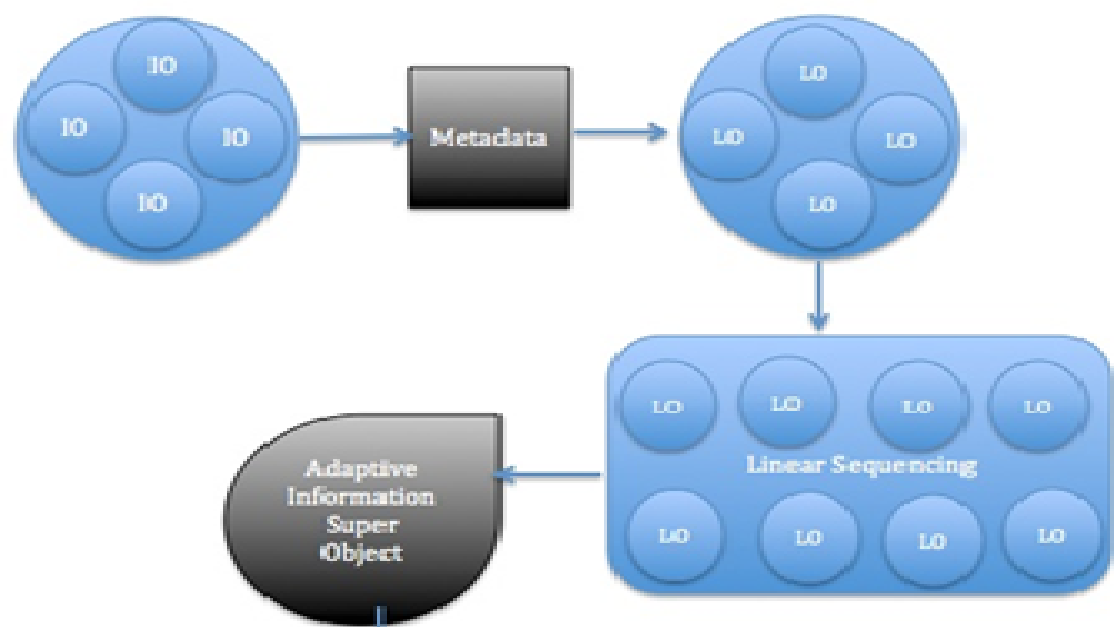

Fig 3. Adaptive Learning Object

Few steps are used to form adaptive learning object. The step are follows [14]

1. Identifying Learning goals

2. Description of target student

3. Teaching methodology strategy

4. Aggregation of learning material or information object.

5. Create metadata - catalogue the related object and index it.

6. Group the related metadata called as Learning Object

7. Now Linear sequencing the related learning object

8. Creation of an adaptive Information super-object 


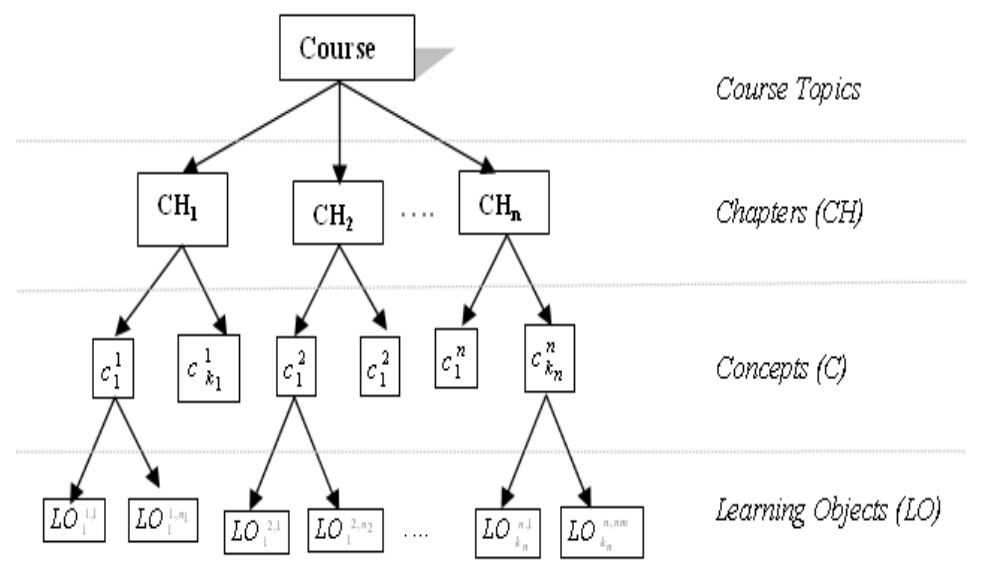

Fig 4. Hierarchical Learning Object

\subsection{Learner / Student Model}

This model grasps the learner profile which contains learner information in e-learning environments. The profile consist of learner identification, area of subject, age, learner interests, learner learning style and his / her previous and current knowledge. These parameter predicts the learner behavior and the learning management system will spontaneously assign learning content and this cognitive parameters predicts goal of relevant information, visual attention. Visual attention is obtained based on the learner attention at the time of studying and the strength of learner's learning performance during problem solving process [15]. This learner model predicts the learner active performance while learning, however, when the learner gets distraction due to psychological behavior or any external environment, we need an additional module to take the control of learner model and retain the learner in focused listening mood by cognitive tutor. This tutor overcome this state by raising external stimuli i.e., related learning material in the form of presentation, audio clip, video clips, questionnaires, diagrammatical representation of the current learning content, any related images or animation clip.

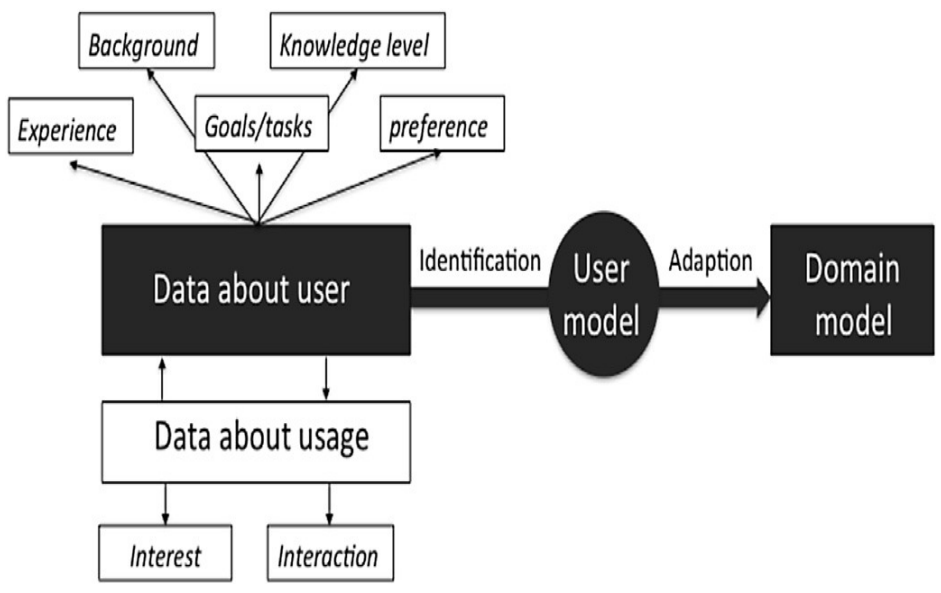

Fig 5. Learner personalization parameter 


\subsection{Proposed Adaptive Cognitive Model}

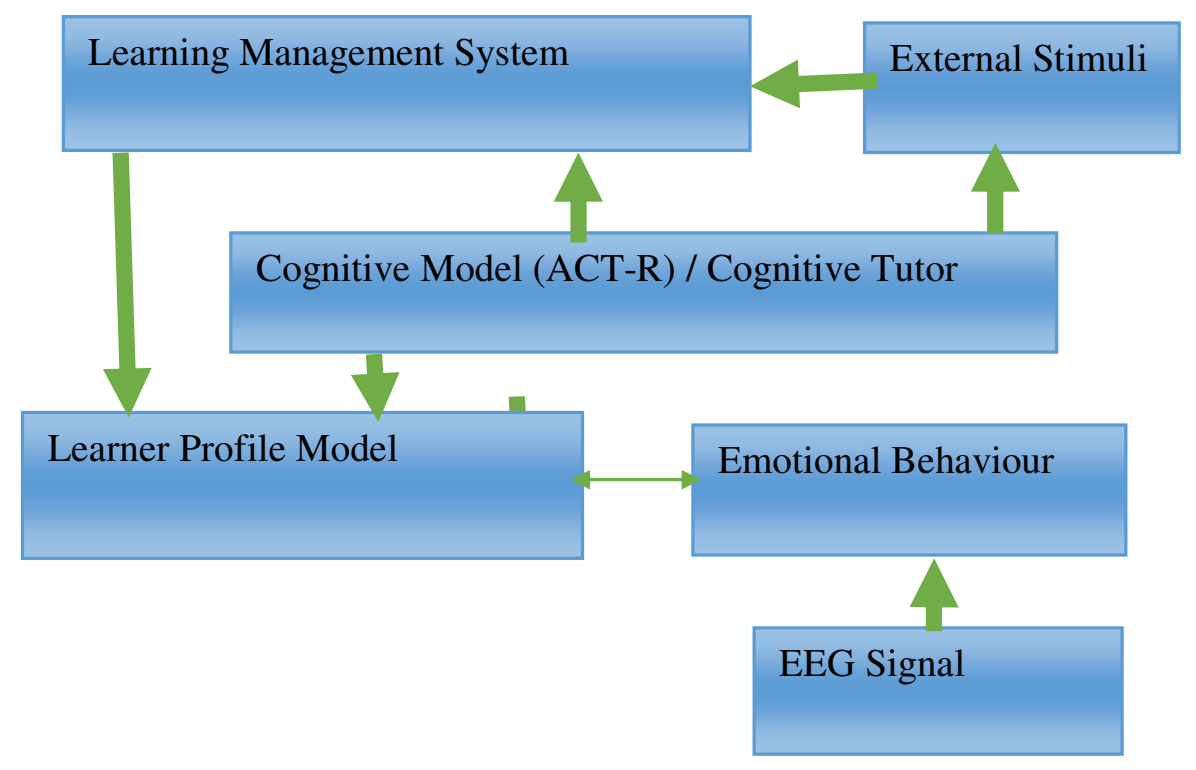

Fig 6. Adaptive Cognitive Model for e-learning

Fig 6 depicts that, the cognitive Model dynamically observes the learner cognitive behavior with respect to their psychological behavior and the other personalization features of e-learner and assign the learning content through learning management system. In addition, the cognitive tutor observe the learner learning distraction based on the learner performance while learning, immediately it raise the external stimuli to direct the learner to active focused mood. The period of time from distraction mood to active listening mood called as psychological refractory period (PRP). This period mainly focused and controlled by cognitive architecture ACT-R. Hence this proposed adaptive architecture provides the platform for e-learner as pedagogical learning environment.

\section{IMPLEMENTATION AND RESUlt ANALYSIS}

Many authors are more comfortable with the idea of "repurposing" content instead of reusing it without exception. Typically, authors find adaptive learning objects a useful "base" for content that they can modify to fit their specific needs. To overcome this challenge, each organization should look at the possible return on investment (ROI) of reuse versus repurposing, and the level of change allowed for any existing learning object. Based on the level of ROI required by the organization, authoring guidelines can be established. It is easy to get caught up in a debate over granularity, content, continuity, and context that takes away from other reasons for adopting an RLO strategy[16][17].

In this proposed work, first, we have taken available reusable learning from World Wide Web and allow twenty student to take this subject like "System Software" for one hour course, periodically, we are monitoring the learner behaviour and their performance by assigning repeated test. The progress were marked (Fig7). 


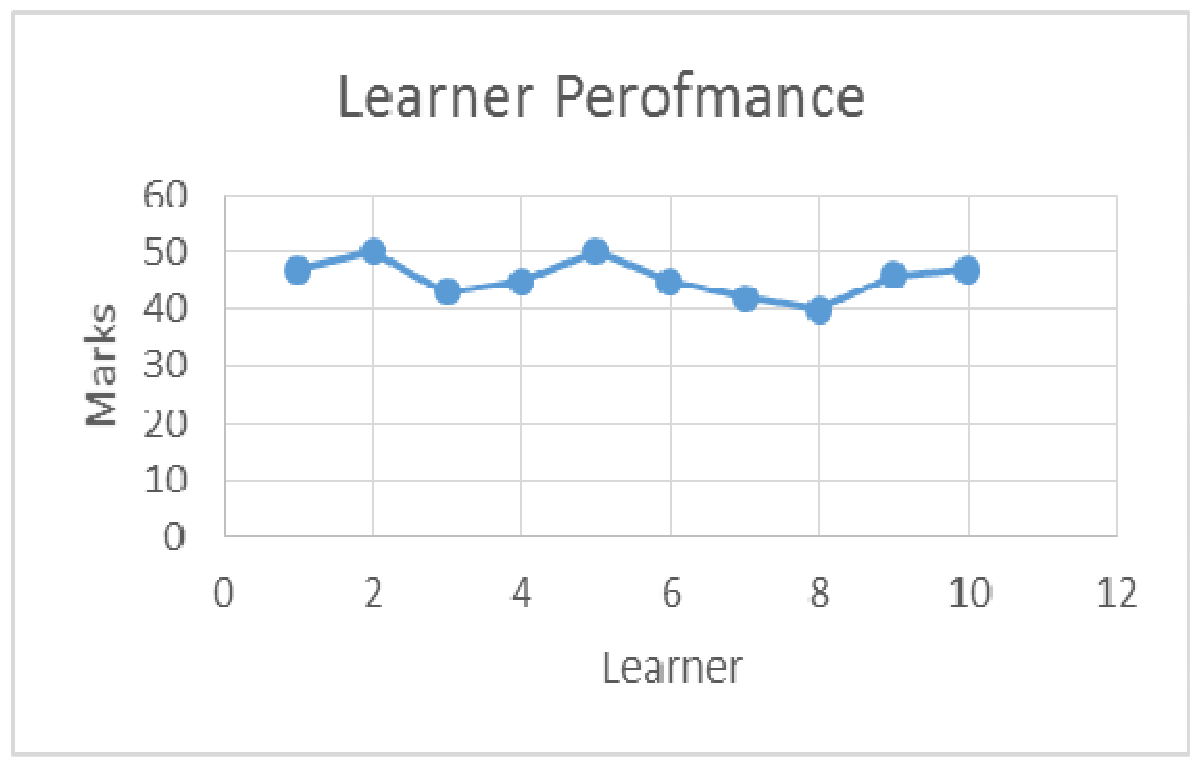

Fig7. Learner Performance without cognitive control

Fig 8 depicts that, we continue the same course for different set of student along with external stimuli, i.e., whenever the learner gets distraction, then the cognitive tutor immediately raise or trigger the related external stimuli. When the student or learner gets various form of learning content like pedagogical tutor calling the distracted student with his/ her name or throwing chock piece to the concern person. If the pedagogical tutor triggering the student like the above steps, then the student will get into normal mood. However, in e-learning, the cognitive tutor does the same way of directing the learner to active mood by raising external stimuli wherever or whenever needed. This progress was recorded.

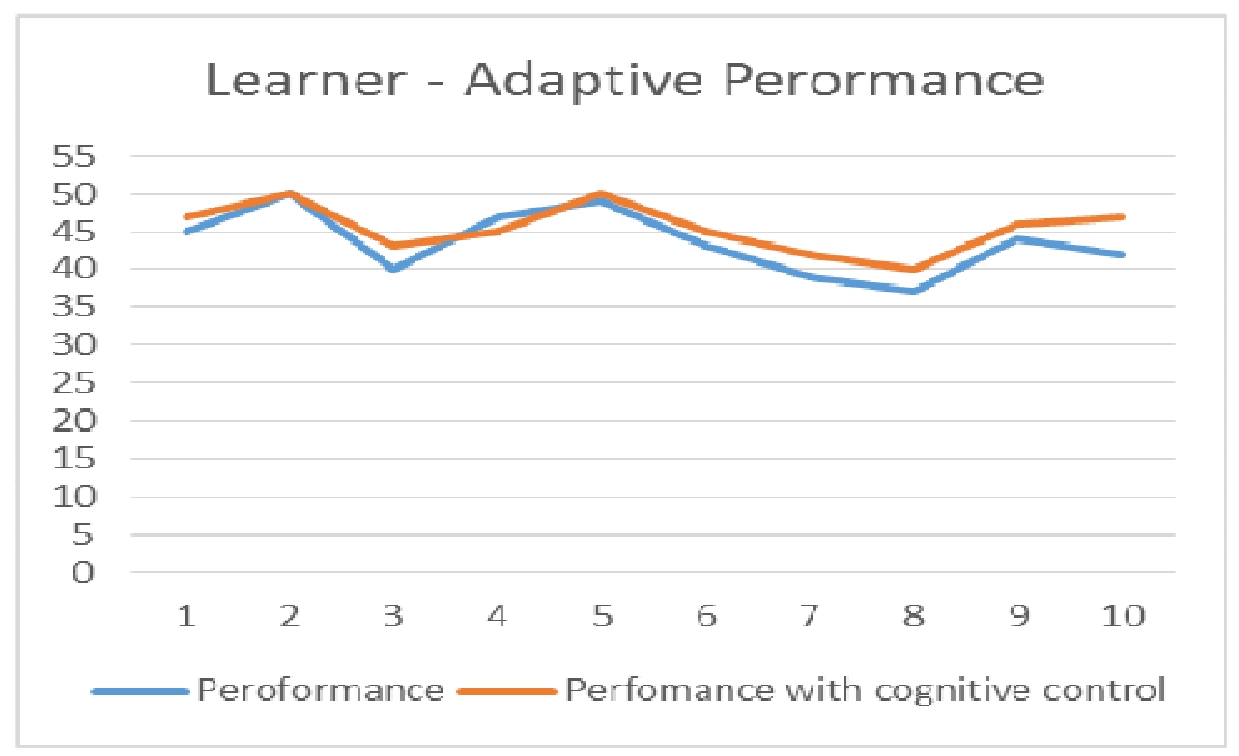

Fig 8. Learner performance with cognitive control 
Advanced Computing: An International Journal (ACIJ), Vol.7, No.1/2, March 2016

Secondly, we have taken audio based learning content like NPTL learning repositories, why are choosing this portal is, this audio lecture note purely prepared by Indian professors and specifically for engineering based subjects. In addition, to simulate pedagogical environment, we have to offer audio learning content to e-leaner as pedagogical tutor teaching. Then we noted that, the understanding capability of learner while learning will differ with respect to the structure of learning content.

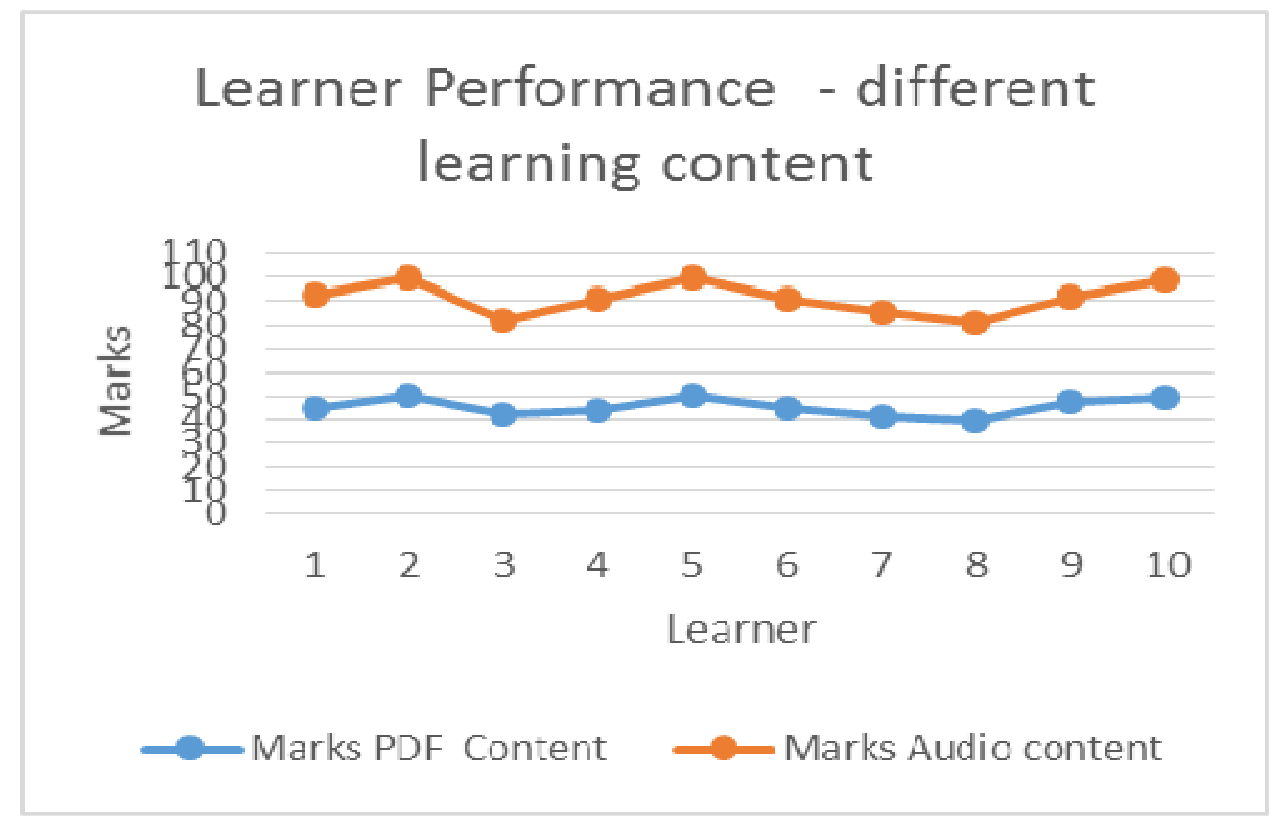

Fig 9. Learner Performance with respect to the Learning content

Our reusable learning object mainly focusing to create Meta data structure for external stimuli related to our learning content. The question sets to test the learner's knowledge to monitor the progress of e-learner.

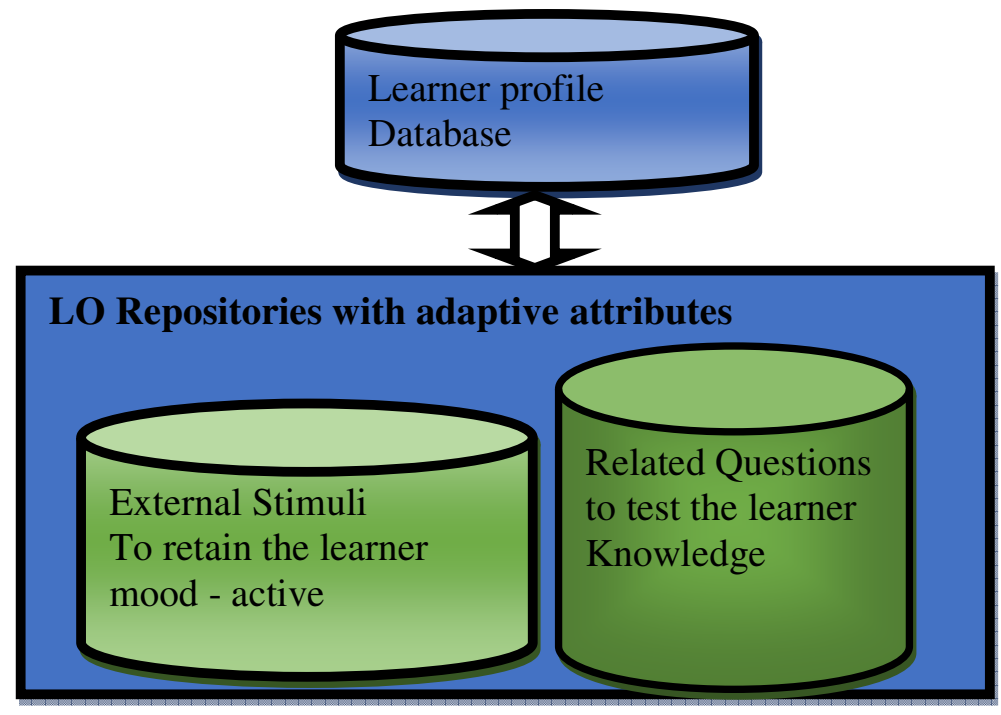

Fig 10. Learning Object - Workspace 
Fig10. Depicts that, this proposed work mainly focusing to develop repository for stimuli files and the required learning material to test the learner knowledge. These stimuli are trigged with respect to the learner listening mood. There are many benefits for adopting an adaptive Reusable Learning Object strategy and many challenges that need to be overcome. They can range from tools and systems to writing styles and guidelines. Some challenges may be significant enough to limit the scope of your learning object strategy or require you to phase in the strategy over time. We cannot anticipate every challenge that we may face, but they can be combated using intellectual brainstorming and innovative ideas.

\section{CONCLUSION}

Adaptive reusable objects, in terms of being great help in the education industry will achieve great strides in transforming the current trends of the education system in Future. In this paper, we present a definition of learning objects, Reusable learning object and Learning Management System. Then we included external stimuli related to our learning content in reusable learning object learning material. Finally, we described how the external stimuli were monitored and triggered by cognitive tutor with respect to their performance. In future, we are planning to include real time emotional data of e-leaner to observe the exact cognitive behaviour of e-learner while learning and how this RLO material reused for other learner. This learning environment comparatively may give enhanced and appealing environment for e-learner.

\section{REFERENCES}

[1] Peter Brusilovsk, Vincent P. Wade and Owen Conlan, "From Learning Objects to Adaptive Content Services for ELearning",

[2] Barritt C. and F. Lee Alderman. 2004. Creating a Reusable Learning Objects Strategy. John Wiley \& Sons Inc., San Francisco, CA.

[3] McGreal R. 2004. Online Education Using Learning Objects. Rutledge Publ., New York, NY.

[4] Polsani P.R. 2003. Use and abuse of Reusable Learning Objects. J. of Digital Information 3(4)No.164.Available at: http://jodi.ecs.soton.ac.uk/Articles/v03/i04/Polsani/

[5] Eileen costelloe, Elizabeth sherry, Patricia magee, "Combining concept maps and reusable Learning objects to promote reflection in Novice programmers", celda 2007.

[6] Dr Mutlag Alsubaie, Greater Manchester, 2009 Reusable Objects: Learning Object Creation Cycle, Second International Conference on Developments in eSystems engineering.

[7] Claudine A. Allen, Ezra K Mugisa, "Improving Learning Object Resuse Through OOD: A Theory of Learning Objects", JOT 2010

[8] Susan Curtis, Matthew Love \& Elizabeth Uruchurtu,"Creation of reusable learning objects to support the teaching and learning of key introductory concepts in Database Systems".

[9] Aroyo, L., \& Dicheva, D. "The New Challenges for E-learning", The Educational Semantic Web. Educational Technology \& Society, vol 7 (4), pp 59-69. 2004.

[10] Zarqa University, Jordan," Multi-Adaptive Learning Objects Repository Structure Towards Unified E-learning", International Arab Journal of e-Technology, Vol. 3, No. 3, January 2014

[11] Terese Liada, "ACT-R: A cognitive architecture", Seminar AI Tools

[12] Jacob Whitehill," Understanding ACT-R \{an Outsider's Perspective”.

[13] Margaret M.Bradley and Peter J. Lang, University of Florida," Measuring emotion:the selfassessment manikin and the semantic differential", Pergamon, Center for Research in Psychophysiology, Box 100165 Health Sciences Center, University of Florida, Gainesville, FL, 32610, U.S.A.

[14] A.Kanimozhi 1 Dr. V.Cyrilraj 2, “ An Adaptive Consistent Architecture to Enhance Reusable Learning Object System for E-Learning”, ACS - International Journal in Computational Intelligence, Volume - 05, Issue - 02 December 2014

[15] Vatcharaporn Esichaiku, Supaporn Lamnoi, Clemens Bechter, "Student Modelling in Adaptive ELearning Systems”, Knowledge Management \& E-Learning: An International Journal, Vol.3, No.3. (2011) 
Advanced Computing: An International Journal (ACIJ), Vol.7, No.1/2, March 2016

[16] Ayidh Alanazi(\&) and Maysam Abbod, "E-Learning Repository System for Sharing Learning Resources Among Saudi Universities", (C) Institute for Computer Sciences, Social Informatics and Telecommunications Engineering 2014, G. Vincenti et al. (Eds.): eLEOT 2014, LNICST 138, pp. 1018, 2014. DOI: 10.1007/978-3-319-13293-8_2

[17] Susan Smith Nash, "Learning Objects, Learning Object Repositories, and Learning Theory:

Preliminary Best Practices for Online Courses", Interdisciplinary Journal of Knowledge and Learning Objects Volume 1, 2005 